\section{Hemophagocytic lymphohistiocytosis and Pelger-Huët anomaly associated with colchicine intoxication}

\author{
Baris Malbora, ${ }^{1}$ Emine Polat, ${ }^{2}$ \\ Sare Gulfem Akyuz ${ }^{3}$
}

Departments of ${ }^{1}$ Pediatric Hematology, ${ }^{2}$ Pediatrics, ${ }^{3}$ Pediatric Nephrology, Dr. Sami Ulus Research and Training Hospital of Women's and Children's Health and Diseases, Ankara, Turkey

\section{Abstract}

Colchicine is frequently used in the treatment of familial Mediterranean fever (FMF). First symptoms of colchicine intoxication are gastrointestinal disturbances, such as abdominal cramps, diarrhea, pancytopenia and so on. Herein, we report a female FMF patient with pancytopenia and hemophagocytic lymphohitiocytosis (HLH), following colchicine intoxication for committing suicide. To our knowledge, this is the first reported case of a patient with HLH associated with colchicine intoxication.

\section{Introduction}

Colchicine is a widely used drug for treatment of familial Mediterranean fever (FMF). Clinical manifestations of colchicine intoxication include abdominal cramps, diarrhea, myotoxicity, hemolytic anemia and (pan)cytopenia. ${ }^{1-3}$ Yet, colchicine intoxication related hemophagocytic lymphohitiocytosis (HLH) has not been reported.

\section{Case Report}

A 9-years-old female patient, receiving colchicine for four months with a dose of 1 $\mathrm{mg} /$ day for FMF, was admitted to a hospital with gastrointestinal disturbance four days ago. She was referred to our hospital with liver and kidney dysfunction. At the initial physical examination the patient's general condition was moderate, and she was conscious. Her weight was $30 \mathrm{~kg}$. She had hepatomegaly.

Her laboratory results revealed: hemoglobin $13.6 \mathrm{~g} / \mathrm{dL}$; leukocyte, $9.6 \times 10^{9} / \mathrm{L}$; thrombocyte $57 \times 10^{9} / \mathrm{L}$; fibrinogen $157 \mathrm{mg} / \mathrm{dL}$ (230-500); PT 26.1 sec; INR 2.3; aPTT 43.8 sec; LDH 5329 IU/L; AST 630 IU/L; ALT 52 IU/L; ferritin 2320 $\mu \mathrm{g} / \mathrm{L}(10-55)$; triglyceride $7.1 \mathrm{mmol} / \mathrm{L}(0.32$ -

1.46). Microbiologic serologies were negative.

The patient was taken to intensive care unit; vitamin $\mathrm{K}$ and fresh frozen plasma were administered. On the second day of her hospitalization, she had $39^{\circ} \mathrm{C}$ fever and splenomegaly. Hemoglobin was $9.6 \mathrm{~g} / \mathrm{dL}$; leukocyte was $2.3 \times 10^{9} / \mathrm{L}$; neutrophil was $0.72 \times 10^{9} / \mathrm{L}$ and thrombocyte was $24 \times 10^{9} / \mathrm{L}$. On peripheral blood smear, loss of lobulation in neutrophils was detected (Pelger-Huët anomaly). Laboratory tests revealed ferritin $54,632 \mu \mathrm{g} / \mathrm{L}$, triglyceride $7.4 \mathrm{mmo} / \mathrm{L}$, and fibrinogen $63 \mathrm{mg} / \mathrm{dL}$, serum creatinine $3.2 \mathrm{mg} / \mathrm{dL}$ (0.4-1.4), serum blood urea nitrogen $43 \mathrm{mg} / \mathrm{dL}$ (6-21), serum sodium $131 \mathrm{meq} / \mathrm{L}$ (134-148), potassium $5.2 \mathrm{meq} / \mathrm{L}$ (34.8), calcium $8.1 \mathrm{mg} / \mathrm{dL}$ (7.9-9.9), and inorganic phosphate $2.1 \mathrm{mg} / \mathrm{dL}$ (2.4-4.7). At the bone marrow aspiration, many Pelger-Huët cells were observed. Hemophagocytosis was detected (Figure 1). Soluble CD25 level was $2840 \mathrm{U} / \mathrm{mL}$ (220-710), and creatine kinase level was 18,959 IU/L. Myoglobinuria was spotted.

When the history of colchicine intoxication was detailed, during FMF attack-free period of five days prior to admission to the hospital, it is learned that the patient was upset over a quarrel between her parents, and that she had taken approximately 30 pills of her drug (total of $15 \mathrm{mg} ; 0.5 \mathrm{mg} / \mathrm{kg}$ body weight), at which vomiting and diarrhea complaints were started. Then laboratory and clinical findings of the HLH have emerged. The patient was administered HLH-2004 protocol and plasma exchange is applied twice. On the second day of therapy, severe hypotension, renal failure and AV complete block occurred. The patient was resistant to all therapies and had died at the fourth day of her hospitalization.

\section{Discussion and Conclusions}

In the colchicine intoxication, the most affected organs are those that have a rapid cell turnover. First symptoms of acute toxicity are gastrointestinal disturbances. Liver damage, renal failure, arrhythmias, neuromuscular disturbances, and bone marrow depression can be detected in the later stage. ${ }^{3,4}$

The worst predicted doses were classified regarding the risk of toxicity as sub-toxic $(<0.5$ $\mathrm{mg} / \mathrm{kg}$ ), toxic $(0.5-0.8 \mathrm{mg} / \mathrm{kg})$, and lethal ( $>0.8$ $\mathrm{mg} / \mathrm{kg}$ ) doses. ${ }^{5}$ However, cases with cardiogenic shock and death were also reported with doses less than $0.5 \mathrm{mg} / \mathrm{kg} .{ }^{6}$ Although our patient had taken a dose of $0.5 \mathrm{mg} / \mathrm{kg}$ body weight colchicine, the patient died due to severe myelosupression, HLH and multi-organ failure.

Pelger-Huët anomaly is a state of limitation in segmentation of lobes in neutrophils. A Pelger-Huët-like change in granulocyte morphology may occur as an acquired condition in
Correspondence: Baris Malbora, Department of Pediatric Hematology, Dr. Sami Ulus Research and Training Hospital of Women's and Children's Health and Diseases, Babur Caddesi 44, Ankara 06080, Turkey.

Tel.: +90.312.305.6000 - Fax: +90.312.317.0353.

E-mail: barismalbora@gmail.com

Key words: colchicine intoxication, hemophagocytic lymphohitiocytosis, Pelger-Huët anomaly.

Acknowledgements: the authors would thank Nihan Malbora for his help with the English editing of the manuscript.

Contributions: the authors contributed equally.

Conflict of interests: the authors declare no potential conflict of interests.

Received for publication: 17 February 2014.

Revision received: 20 April 2014.

Accepted for publication: 20 May 2014.

This work is licensed under a Creative Commons Attribution NonCommercial 3.0 License (CC BYNC 3.0).

(C) Copyright B. Malbora et al., 2014

Licensee PAGEPress, Italy

Hematology Reports 2014; 6:5356

doi:10.4081/hr.2014.5356

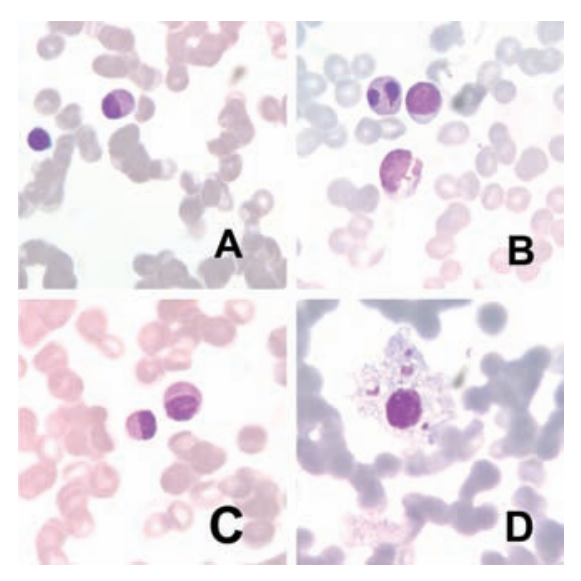

Figure 1. Pelger-Huët anomaly with a unilobed ovoid nucleus. The nucleus is smaller with more compact and densely staining chromatin on the peripheral blood smear (A) and bone marrow aspiration (C) (Wright-Giemsa, 100×, oil immersion). Pelger-Huët anomaly with bilobed polymorphonuclear leukocyte with a short, thick nucleus and dense, darkly staining chromatin, most consistent with a mature PMN on the peripheral blood smear (B) (Wright-Giemsa, 100x, oil immersion). Bone marrow aspirate of the patient showing phagocytosis of platelets (D) (WrightGiemsa, $100 \times$, oil). 
several diseases. ${ }^{7,8}$ This same finding may be produced by certain drugs such as colchicine. ${ }^{9}$ On the peripheral blood smear of our patient, Pelger-Huët cells were detected in myeloid series, and as the history of colchicine use was detailed, it is learned that the patient had taken lots of colchicine pills. On the examination of concurrently taken bone marrow, Pelger-Huët cells were also detected in the myeloid series as well as hemophagocytosis.

Association between HLH and FMF has been shown. ${ }^{10,11}$ Although our patient had FMF diagnosis, she was in stabile state. For this reason, we suggest that HLH was not due to her disease. To our knowledge, this is the first reported case of a patient with HLH associated with colchicine intoxication.

In conclusion, if patients with colchicine intoxication present with Pelger-Huët anomaly in addition with unexplained fever, cytopenia, organomegaly, and biochemical changes, HLH should be investigated for prompt diagnosis and treatment.

\section{References}

1. Todd BA, Billups SJ, Delate T, et al. Assessment of the association between colchicine therapy and serious adverse events. Pharmacotherapy 2012;32: 974-80.

2. Lee KY, Kim DY, Chang JY, Bang D. Two cases of acute leucopenia induced by colchicine with concurrent immune-suppressants use in Behcet's disease. Yonsei Med J 2008;49:171-3.

3. Guven AG, Bahat E, Akman S, et al. Late diagnosis of severe colchicine intoxication. Pediatrics. 2002;109:971-973.

4. Maxwell MJ, Muthu P, Pritty PE. Accidental colchicine overdose. A case report and literature review. Emerg Med J 2002;19:265-7.

5. Niel E, Scherrmann JM. Colchicine today. Joint Bone Spine 2006;73:672-8.

6. Montiel V, Huberlant V, Vincent MF, et al.
Multiple organ failure after an overdose of less than $0.4 \mathrm{mg} / \mathrm{kg}$ of colchicine: role of coingestants and drugs during intensive care management. Clin Toxicol (Phila) 2010;48:845-8.

7. Dorr AD, Moloney WC. Acquired pseudoPelger anomaly of granulocytic leukocytes. N Engl J Med 1959;261:742-6.

8. Linman JW, Saarni MI. The preleukemic syndrome. Semin Hematol 1974;11:93-100.

9. Colella R, Hollensead SC. Understanding and recognizing the Pelger-Huët anomaly. Am J Clin Pathol 2012;137:358-66.

10. Rossi-Semerano L, Hermeziu B, Fabre M, Koné-Paut I. Macrophage activation syndrome revealing familial Mediterranean fever. Arthritis Care Res (Hoboken) 2011; 63:780-3.

11. Uslu N, Demir H, Balta G, et al. Hemophagocytic syndrome in a child with severe Crohn's disease and familial Mediterranean fever. J Crohns Colitis 2010;4:341-4. 